\title{
"Las mujeres despiertas": el papel del género en el control de un terreno comunal en los Andes peruanos
}

\author{
Daniel Escobar López ${ }^{1}$
}

Recibido: 13 de febrero de 2017 / Aceptado: 17 de abril de 2017

Resumen. El presente texto tiene como objetivo explorar el papel de las relaciones de género en el control y uso de un terreno comunal en una comunidad campesina de los Andes peruanos. El contexto general es el turismo y el más reciente proceso de privatización de tierras que, si bien empezó años atrás, se vio acelerado recientemente por el proyecto de construcción de un aeropuerto internacional en las cercanías de la comunidad. Veremos cómo el surgimiento de un atractivo turístico (El Mirador) y la consecuente formación de una asociación artesanal han afectado las relaciones de género locales y la participación política de las mujeres.

Palabras clave: Género; turismo; tierras comunales; infraestructuras; titulación de tierras; agencia; Andes peruanos.

\section{[en] "The awakened women": The role of gender in the control of a commu- nal land in the Peruvian Andes}

\begin{abstract}
This article aims to explore the role of gender relations in the control and use of communal land in a peasant village located in the Peruvian Andes. The context is the current process of acquiring land private deeds, which even though began several years ago, in the region, has been speeded-up by the current plans to build an international airport closed to the village. We will discuss how the emergence of a tourist attraction (El Mirador) and the consequent formation of a female handicraft association has affected the gender configurations of the village and helped to raise women's political participation.
\end{abstract}

Keywords: Gender; communal lands; tourism; infrastructure; land titling; agency; Andes.

Sumario. 1. Introducción: planteamiento del problema a través de un registro etnográfico. 2. Marco conceptual. 2.1. Género en Latinoamérica. 2.2. "Las mujeres son más indias": género, raza, etnicidad y turismo en los Andes. 2.3. Agencia. 3. Antecedentes: tierra, comunidad y titulación. 4. El Mirador en la narrativa: turismo e historias de invasión. 4.1. "De una colina a un mercado artesanal": la inscripción de las historias en las obras. 4.2. El Mirador es nuestra obra: legitimación del poder local. 4.3. El Mirador y los usos locales de la tierra. 5. El papel del género en las disputas por El Mirador. 5.1. "Las mujeres despiertas": participación de mujeres en la asamblea comunal. 5.2. Mujeres organizadas y warmichas: construcciones de género global y local. 6. Discusión: agencia y división del trabajo.7. Reflexiones finales. 8. Referencias bibliográficas.

Cómo citar: Escobar López, D. (2017). "Las mujeres despiertas": el papel del género en el control de un terreno comunal en los Andes peruanos, en Revista de Antropología Social 26(2), 307-332.

\footnotetext{
1 Licenciado en Antropología por la Universidad de San Antonio Abad del Cusco, Perú y doctorando en Antropología Social en la Universidad de Estocolmo. daniel.escobar@socant.su.se
} 


\section{Introducción: planteamiento del problema a través de un registro etnográfico ${ }^{2}$}

Hoy, como todos los días de febrero de 2014 , los rayos de sol se asoman puntuales a las cinco y media de la mañana en Pumapuqllo, una comunidad campesina quechua en los Andes peruanos, distrito de Chinchero ${ }^{3}$, departamento del Cusco. Pero, a diferencia de otros días del "mes de las lluvias" (como los cusqueños solemos decir), la ausencia de nubes permite al cielo revelar ese típico color azul intenso, tantas veces retratado en las postales que a diario compran los turistas que visitan el distrito de Chinchero 4 .

Estamos en la comunidad campesina de Pumapuqllo, habitada por unas cien familias y situada a menos de seis kilómetros de la capital de distrito y a unos treinta de la ciudad de Cusco, la antigua capital inca y una de las ciudades más turísticas de Perú. A casi 3.800 metros sobre el nivel del mar, el viento helado golpea duro a estas horas del día. Me dispongo a subir al Mirador, una colina ubicada en terrenos comunales de Pumapuqllo, muy cerca del límite con la comunidad de Wayraqpunco y al lado de la carretera principal que conecta esta parte de Cusco con Lima y el resto del país. A lo lejos, desde esta altura, logro distinguir a los primeros comuneros bloqueando la carretera con piedras, palos, neumáticos y banderolas buscando impedir el tránsito vehicular por esta zona. Por medios radiales se informa que es el inicio de la huelga regional de 72 horas en contra del gobierno central por la suspensión de la concesión de las obras del Gasoducto Sur Peruano (GSP) y el retraso en la entrega de la buena pro (adjudicación de un contrato público con el Estado peruano) para la construcción del Aeropuerto Internacional de Chinchero 5 (Diario La República 25-02-2014).

La prensa añade que otra razón de la protesta es el recorte del canon gasífero y minero a las municipalidades y gobiernos regionales en todo el país (Diario Correo 25-02-2014). Sin embargo, otra obra está en juego en la comunidad: El Mirador, una colina que después de volverse un atractivo turístico a finales de los 90 , fue transformada años después en un mercado artesanal por las mujeres de la Asociación Artesanal Tres Lagunas.

Esta asociación fue creada en el año 2000 por la comunidad de Pumapuqllo como parte de su estrategia comunal de defensa de su territorio ante vendedores foráneos. Cuenta con 32 socias (todas mujeres excepto un varón). Después de su formación y la elección del primer presidente por parte de la comunidad, el control de la asocia-

2 Este artículo está basado en datos recolectados entre 2006 y 2009, un largo trabajo de campo entre 2013 y 2014 y una visita corta los años 2015 y 2016. El trabajo de campo se realizó tanto en el distrito de Chinchero, Valle Sagrado de los Incas como en la ciudad del Cusco.

3 Para salvaguardar la identidad de las personas involucradas en el presente estudio, el nombre de la comunidad, la asociación artesanal y los nombres de los informantes han sido cambiados utilizando seudónimos para todos los casos. A excepción de una comunidad vecina, el resto de lugares como Chinchero conservan sus verdaderos nombres.

$4 \quad$ El distrito de Chinchero pertenece a la provincia de Urubamba y está localizado en el departamento del Cusco. Tiene una población de un poco más de 9.000 habitantes que viven en la capital del distrito Chinchero y otras 16 comunidades campesinas.

5 Este último ha sido catalogado como uno de los proyectos peruanos de infraestructura más importantes de los últimos años (con una inversión de más de 300 millones de dólares americanos) y tiene por finalidad reemplazar al actual aeropuerto de la ciudad del Cusco, convirtiéndose así en el segundo mayor aeropuerto internacional peruano. 
ción y El Mirador, después de un par de años, quedó en manos de sus socias, ocasionando algunas tensiones con la comunidad.

Hoy de madrugada y como en otras ocasiones, las socias se han reunido para coordinar acciones en defensa del Mirador, esta vez ante la familia que años atrás donó el terreno y que hoy reclama una compensación. No es la primera vez que esta familia hace este reclamo, pero a diferencia del pasado, hoy están dispuestos a ir hasta las últimas consecuencias. El motivo según ellos es el alza del precio de los terrenos en todo Chinchero por el anuncio de la construcción del aeropuerto. Terrenos como el del Mirador se han vuelto especialmente codiciados por encontrarse cercanos a las vías de comunicación terrestre.

La primera acción de las socias esa mañana fue realizar una faena para deshierbar y limpiar los puestos de venta que no usan, el salón donde se reúnen una vez al mes, el cuarto destinado a ser cocina pero que ahora sirve de depósito, el baño que alquilan a turistas, los postes de luz que por ahora no tienen electricidad y el piso donde aparcan los buses y donde venden sus artesanías. ¿Por qué limpiar construcciones que, a excepción del baño, aparentemente no tienen uso? Una socia nos lo explica:

Hemos hecho faena, limpieza [...] Ayer en la mañana nosotros hemos pensado: de repente el dueño va a decir: acá no utilizan ipor gusto están las chozas! [Puestos de venta]; entonces, para que no digan eso, para ganar [la disputa a la familia] hay que hacer limpieza. [...] cien por ciento nosotros vamos a ganar. Ayer fuimos a hablar con el Gobernador y él y todos han dicho eso, la abogada ha dicho eso también. (Irene, 48 años)

La otra estrategia, como otra socia me explicaba, fue convencer a la Asamblea de que era la comunidad y no ellas quien debía compensar a la familia, ya que El Mirador se encuentra, después de todo, en un terreno comunal. Esta faena dio sus frutos, como atestigüé cinco días después en la asamblea comunal ordinaria. Lo primero a tratar fue si la familia tenía razón en su reclamo. Cuando la familia exigió que el terreno les fuera devuelto porque se encontraba en terrenos de su "propiedad", los miembros de la asociación respondieron que eso era imposible ya que El Mirador no era "lo mismo que en el año 2000" ya que se había transformado en un mercado artesanal donde se habían construido baños, puestos de venta, salones, instalación eléctrica, y demás. "El Mirador es nuestra obra", insistieron las socias.

Después de escuchar los argumentos de la familia y revisar en el libro de actas los acuerdos tomados cuando se formó la asociación, la asamblea resolvió que El Mirador no podría ser devuelto a la familia, pero que debía ser compensada. La pregunta a resolver entonces era quién y de qué manera se procedería. Antes de esta reunión, las socias me informaron de que la familia pedía a cambio un terreno grande o el pago de por lo menos 20 dólares americanos por metro cuadrado (es decir lo que se pagó por los terrenos del aeropuerto), precio que las socias consideraron fuera de su alcance. En la reunión, ya que no era posible pagarles por el terreno, la familia exigió que se le compensara con un terreno de doble del tamaño del Mirador y que estuviera cerca de la pista.

Finalmente, la comunidad decidió compensar a la familia con un terreno comunal de igual tamaño al del Mirador y sin asegurar que fuera al lado de la pista. Después de la reunión, las socias estaban satisfechas pero también preocupadas por las 
consecuencias que dicha reunión podría tener en el futuro, ya que El Mirador fue reafirmado como terreno comunal y las autoridades estaban insistiendo en expulsar a siete socias que no eran parte de la comunidad. A diferencia del pasado, cuando la asociación las defendió, esta vez parecían resignadas a dejar en manos de la comunidad la permanencia de dichas socias. Su esperanza era que una vez que la titulación de tierras individuales concluyera, la comunidad decidiese donarles el terreno, ya que además de la obra que habían hecho en El Mirador, ellas habían pagado por el levantamiento de plano, requisito indispensable para obtener los títulos de propiedad. Con el título de propiedad esperaban poner fin a los conflictos y beneficiar a todas las socias, fueran o no de la comunidad. Esto no llegó a ocurrir y en 2016, El Mirador, finalmente, fue uno de los pocos terrenos que quedaron inscritos a nombre de la comunidad.

Este registro etnográfico sobre una huelga en 2014 ilustra el contexto y las preguntas que abren este artículo sobre las relaciones de género y las negociaciones por el control y uso de la tierra: ¿cuál ha sido el impacto de la formación del Mirador en la actuación política de las socias?, ¿cómo han negociado las mujeres el control del Mirador? y, por último, ¿cómo ilustra este caso las relaciones de género en el actual contexto de turismo, presión y titulación de tierras a raíz de la construcción del aeropuerto en Chinchero? Para responder estas preguntas, presentaré el marco teórico que guía mis respuestas para luego ubicar a la comunidad en el contexto andino.

\section{Marco conceptual}

\subsection{Género en Latinoamérica}

Mi punto de partida es entender el género como una categoría analítica que ayuda a desvelar las relaciones de poder implícitas en la interpretación social de las diferencias anatómicas entre los sexos (Curiel, 2010). Como bien lo señala Lamas (2007), la naturalización de las jerarquías entre varones y mujeres surge cuando se extrapola la complementariedad reproductiva biológica a una complementariedad social para justificar desigualdades económicas, sociales o de acceso diferenciado a recursos (por ejemplo, la tierra) entre varones y mujeres.

La diferencia sexual como base de las relaciones de género ha sido cuestionada por el feminismo, aduciendo que tanto el sexo como el género es una construcción social (Curiel, 2010). Ya en 1973, la feminista materialista Mathieu adelantaba que la diferencia entre varones y mujeres es en realidad una diferenciación, es decir, que esa diferencia es una construcción ideológica y política (Curiel, 2010). Así, las relaciones entre varones y mujeres estarían basadas en relaciones de clase (clases de sexos) enmarcadas en el sistema actual de producción capitalista, la división social del trabajo y los procesos de apropiación de los medios de producción. El resultado sería la domesticación de la sexualidad y la imposición de la heterosexualidad como "norma obligatoria" (Curiel, 2010).

Las críticas al concepto "género" se volvieron aún más complejas cuando las feministas afroamericanas incorporaron al análisis de género otras formas de poder y opresión como la raza (Lugones, 2008; Curiel, 2010; Alvarado, 2016). De esta manera, se opusieron a cualquier intento de universalización del género y la categoría mujer. Uno de sus principales aportes fue el concepto y la meto- 
dología de la interseccionalidad, que afirma que las categorías mujer y varón son hegemónicas y designan al grupo dominante convirtiéndolo en la norma. La interseccionalidad revela el vacío existente entre las categorías dominantes de "mujer" (referida a blanca, burguesa) y "negro" (referido a varón). En ese sentido, las mujeres no blancas fueron marcadas como hembras sin género, "marcadas sexualmente como hembras, pero sin las características de la femineidad" (Lugones, 2008: 94).

En América Latina y el Caribe las intersecciones de género y raza cobran nuevos matices a la luz del concepto de colonialidad del poder del sociólogo peruano Aníbal Quijano, cuyos aportes han tenido marcada influencia en el feminismo y en el así llamado giro de(s)colonial (Yuderkis, 2014). La colonialidad del poder se refiere al patrón de poder actual establecido desde la colonización, en el cual "Europa se constituye en torno a su referencia periférica: América" (Latina) (Curiel, 2010:05). Esta relación se basa en la naturalización de las jerarquías por medio de la invención de la raza, que reordena las jerarquías a nivel global y que se expande con el capitalismo a todos los ámbitos de la vida humana, por ejemplo, en la división global del trabajo. Sobre estas ideas, María Lugones (2008) desarrolla su marco analítico sobre la colonialidad del género al que denomina sistema de género moderno / colonial. Este marco analítico permite ver que las nociones de raza y género definen el acceso a recursos como la tierra, y también el tipo de trabajo, su condición y definición.

Uno de los principales aportes de Lugones (2008) a la teoría feminista en América Latina y el Caribe (y de particular relevancia para este artículo) es su argumento de que la categoría mujer y el patriarcado son fundamentalmente una creación colonial. Según la lectura de Lugones del libro La invención de las mujeres de la feminista africana Oyéronké Oyewùmi, (Lugones, 2008), la idea de que el género es un principio organizador de la vida social es llevado por Occidente a sus colonias y es ahí donde se convierte en una "herramienta de dominación que designa dos categorías sociales que se oponen en forma binaria y jerárquica" (Lugones, 2008: 87). Sin embargo, Segato (2014:15) sostiene que abundantes datos históricos y etnográficos demuestran "la existencia de nomenclaturas de género" en las sociedades indígenas y afroamericanas, en las cuales las categorías de varón y mujer están ordenadas jerárquicamente. Desde antes de la colonia existía en estas sociedades una organización patriarcal pero a diferencia de la occidental, se trataba de un "patriarcado de baja intensidad" (2014:15). Esto significa que en estas sociedades hay jerarquías de género pero estas son "duales", ya que varones y mujeres y las esferas domésticas y públicas son ontológicamente autónomas y provistas de poder y autodefensa. Lo colonial moderno (a través de la colonia primero, la república después y organismos internacionales ahora) profundiza esas jerarquías de género, despolitiza la esfera doméstica y da más poder a los varones, generando así una "hiperinflación" de la masculinidad. Este proceso es reforzado por programas tanto gubernamentales como no gubernamentales que promueven una ciudadanía que refuerza el sistema binario e individualista y una modernidad que esconde la desigualdad bajo un discurso del igualitarismo. A este proceso, la feminista boliviana Paredes (2013) lo denomina "entroque patriarcal", que se refiere al acuerdo tácito entre los intereses del patriarcado occidental y el precolonial. La colonización y la modernización puso a las mujeres bajo dos ejes de dominación: la raza y el género. 


\section{2. "Las mujeres son más indias": género, raza, etnicidad y turismo en los Andes}

De la Cadena (1992) muestra que en la comunidad de Chitapamba - Cusco, las jerarquías sociales implícitas en las relaciones de género se incorporaban a la estratificación étnica, que en muchos casos era la principal fuente de subordinación entre los comuneros. Encuentra que el grado de vinculación con la ciudad divide étnicamente a las personas en "indias", "mestizas" y "en proceso" de mestización. Mientras la gran mayoría de personas consideradas "mestizas" y "en proceso" eran varones, la mayoría considerada dentro de la categoría "indio" eran mujeres. Inclusive las mujeres que migraban a la ciudad y eran consideradas "en proceso", eran percibidas más indias que los varones "en proceso". La percepción de que las mujeres campesinas son más indias trae consecuencias nefastas en sus vidas diarias, ya que están expuestas a una doble marginación: por ser mujeres e indígenas. Además de incentivar la violencia ${ }^{6}$ esta situación desfavorece a las mujeres en el acceso a recursos económicos como la tierra o su expulsión de las esferas de poder. Para Babb (2012), sin embargo, hay algunas ocasiones donde esa cercanía a lo indígena puede ser una ventaja para las mujeres, como en el caso del turismo étnico.

El turismo en la Región del Cusco ha seguido las tendencias nacionales: casi inexistente hasta mediados del siglo XX, foco de políticas estatales e internacionales en los años sesenta y setenta, desapareciendo en los ochenta (debido a la crisis económica y a la violencia política en el país) y recuperándose a finales de los noventa (Fuller, 2008). La bonanza económica de las clases medias y la recuperación de la democracia a fínales del 2000 dinamizaron el turismo interno y externo en todo el país, pasando de 547.423 visitantes en 2002 a 1.689 .766 en 2010 en la región del Cusco (Dircetur, 2014).

Aunque ya desde finales de los setenta las mujeres de Chinchero vendían sus tejidos a turistas en el mercado dominical de Chinchero (Contreras, 1982), es desde la recuperación del turismo a finales de los noventa que la producción de tejidos para el turismo se masifica en el distrito. Aunque la actividad de tejer es y ha sido practicada también por varones ${ }^{7}$, son ellas las representantes del tejido chincherino. La mujer - como en otras partes del mundo donde se promueve el turismo étnico y cultural (Escobar, 2012) - es la que representa lo "auténtico". Esto conlleva que varones y mujeres indígenas experimenten el turismo de diferente manera (Zorn, 2004; Babb, 2011; Ypeij, 2012). Esta participación diferenciada y desigual tiende a profundizar las jerarquías entre varones y mujeres (Zorn, 2004; Henrici, 2007; Babb, 2012), y como diría Segato (2014): la profundización del binarismo de género. Las diferencias basadas en raza, etnicidad y género han sido promovidas por el propio estado peruano. Así, por ejemplo, en 1964 en Pisaq, un poblado cerca de Chinchero,

\footnotetext{
Canessa (2011) muestra que en los Andes bolivianos la violencia hacia mujeres indígenas en sus comunidades es reflejo del racismo al que son sometidos sus esposos en las ciudades. Segato (2014) explica que esta violencia es resultado de la emasculación de los varones en el mundo blanco y mestizo. A este proceso lo denomina "violentogénico" que es la presión por recuperar en la comunidad la virilidad perdida en el mundo urbano.

Muchos de los textiles que se venden ahora en Chinchero son tejidos por presidiarios del centro penitenciario del Cusco. A escala nacional, la actividad artesanal y el tejido han sido realizadas también por varones (ver Contreras, 1982; Zorn 2004)

La vinculación de la mujer con lo auténtico en el contexto del turismo se nutre de representaciones de la mujer como imagen de la nación (Babb, 2012). En el caso peruano, un antecedente está en la idealización que hicieran los intelectuales neoindigenistas cusqueños de principios del siglo XX sobre las mujeres mestizas (indígenas) como representantes de la auténtica cultura cusqueña (De la Cadena, 2000).
} 
el gobierno impulsó programas de producción de cerámica dirigidos solamente a varones, ya que creían erróneamente que las mujeres solo tejían (Henrici, 2007). Como consecuencia, esta actividad se masculinizó, invisibilizando y desvalorizando el trabajo de ceramistas mujeres. Para Henrici, esta jerarquización entre ceramistas y vendedoras, mujeres y varones en la artesanía, es consecuencia de la introducción de nociones occidentales binarias sobre la división del trabajo y el género, que "contrastan masculinidad y feminidad" (2007: 9).

Como adelantaran las feministas antes mencionadas, la categoría "mujer" no es universal y está intersectada con la raza. O como otros académicos prefieren denominar: la indianidad (Weismantel, 2001). Incluso en un poblado tan pequeño como Pisaq, las diferencias entre varones y mujeres del centro poblado (más urbano y mestizo) y de las comunidades campesinas (más rurales e indígenas) están claramente marcadas, lo que tiene consecuencias en el acceso a fuentes de ingreso como el turismo. En general, la participación en el turismo de las comunidades campesinas de Pisaq es escasa y las mujeres campesinas que tejen venden sus tejidos a intermediarios, por ejemplo, a otras mujeres mestizas del centro poblado (Henrici, 2007) ${ }^{9}$. Justamente, el caso de las artesanas del Mirador muestra cuáles son los límites y las negociaciones de las mujeres de comunidades campesinas que han sido excluidas del desarrollo turístico.

Existen, sin embargo, situaciones donde la participación en el turismo puede ser beneficiosa para las mujeres. Es el caso de las artesanas de Chiapas (Babb, 2011) y de algunas artesanas en la región del Cusco (Ypeij, 2012) quienes han usado a su favor el hecho de ser "las representantes auténticas de la cultura", transformándolo en capital cultural y en una oportunidad para sacar réditos económicos (Babb, 2011;Yepij, 2012,). Esta situación, según Yepij (2012), puede ser una oportunidad también para invertir los roles de género y promover la movilidad social femenina. Sin embargo, como mostraré en este texto, la obtención de dinero por parte de las mujeres del Mirador se ha incorporado como parte de sus labores femeninas, sin que eso haya significado necesariamente "invertir" el orden de género. Este último punto tiene que ver con la relación entre agencia y estructura.

\subsection{Agencia}

La teoría de la práctica reconoce que los seres humanos son agentes activos de su propia historia y no meramente productos de las estructuras sociales. A la capacidad de estos actores de reflexionar sobre sí mismos y actuar sobre su entorno social se le ha llamado agencia (agency). Como muchos autores sugieren (Connell, 2002; Warldow, 2006; Curtis, 2009) esta capacidad de actuar, sin embargo, no fluye libremente, sino que se da en interacción constante con la estructura social. Warldow (2006) afirma que debido a que ocupan diferentes posiciones de poder en la sociedad, existen formas particulares de ejercer agencia entre varones y mujeres, lo que denomina una agencia engenerada ${ }^{10}$ (gendered agency). Además, distingue dos modos diferentes

Según Contreras (1982), la presencia de intermediarios en la comercialización de artesanías hechas por campesinos ya se daba desde finales de los 70 en los Andes. Estos intermediarios podían ser comerciantes urbanos o las propias mujeres que residían en centros urbanos, como en el centro poblado de Chinchero.

10 Tomando como referencia la nota del traductor del artículo de Segato (2014), engenerado o engenerar si bien no son parte del vocabulario de la Real Academia Española, aquí como en muchos textos sobre género en La- 
de ejercer agencia entre las mujeres de una comunidad rural en Nueva Guinea: emcompassed agency y negative agency. La primera se refiere a la capacidad de actuar de las mujeres siguiendo las normas y expectativas que la sociedad tiene de ellas. Podría pensarse que su agencia es inexistente ya que aceptan su posición inferior a los varones, pero Warldow sostiene que su agencia no está suprimida, sino incluida (encompassed) en proyectos y agendas más allá de sí mismas. No se sienten excluidas o sin poder, ya que a través de sus roles como mujeres (criar cerdos y cuidar la casa) están contribuyendo a lo que es importante para su familia y su sociedad. Para Warldow (2006) la agencia "negativa" es el rechazo de algunas mujeres de Papua Nueva Guinea a ser incluidas en el proyecto de otros; es retirar sus cuerpos de la reproducción social de sus clanes para su propio beneficio personal. Ambos tipos de agencia, sin embargo, se forman en interrelación con la estructura, no fuera de ella.

A luz de este marco teórico analizaré qué significa la categoría mujer en el contexto de una comunidad campesina y cómo esa categoría define el acceso a medios de producción (tierra y turismo), el tipo de trabajo y el actuar político. Asimismo, veremos la agencia de las socias del Mirador a través de sus negociaciones y reflexiones sobre las estructuras de género, la división del trabajo y el acceso a la tierra. Además, la posición social de las socias es cambiante y se enmarca en las interacciones históricas entre poderes regionales, nacionales y locales.

\section{Antecedentes: tierra, comunidad y titulación}

En Pumapuqllo, al igual que en otras áreas de los Andes (Eguren et al., 2009; Díez, 2014), la distribución de la tierra entre comuneros se da mayormente a través de parcelas familiares. Asimismo, los derechos para hacer uso de estos terrenos familiares son otorgados únicamente por la asamblea comunal. Para ser comunero y tener derecho a usar la tierra se necesita poseer un terreno en la comunidad (principalmente por herencia o transferencia interna) y pasar un periodo de tres años de prueba, asistir a las reuniones y faenas comunales, estar al día en las cuotas y multas y "pasar cargos" o "servir a la comunidad" ocupando puestos tradicionales (varayoq) o los más recientes y prestigiosos cargos de la junta directiva.

Ya que el principal rol de la comunidad es salvaguardar el territorio, no es raro escuchar a ex-autoridades comunales resaltar sus logros en promover la titulación y recuperación de tierras comunales. Como en otros lugares (Burneo, 2012) la tierra define la lucha, la razón de ser y la pertenencia a la comunidad. La asamblea comunal, además de gestionar los bosques, el agua de regadío y las canteras, ha destinado tierras comunales para proyectos o, por ejemplo, para la construcción de su salón comunal. La comunidad controla el acceso a la tierra, solucionando conflictos y poniendo límites en caso de transferencia de terrenos a otros miembros de la comuni$\operatorname{dad}^{11}$.

Desde antes de su reconocimiento jurídico, la comunidad, a través de su asamblea comunal, coordinaba con agentes externos, como el Estado peruano, la construcción

tinoamérica se traduce del inglés gendered que "hace referencia a la negociación intersubjetiva de los arreglos referidos a masculinidad y la femineidad" (Segato, 2014).

11 La venta de tierras a personas de fuera de la comunidad está prohibida, aunque en otras comunidades las personas recuerdan que alguna vez se hicieron tales transacciones, pero de manera irregular. 
de infraestructuras en la comunidad. En 1989, por ejemplo, se formó el Comité de Construcción y Desarrollo para coordinar e implementar varias obras en Pumapuqllo (obras agrícolas y para el bienestar del sector) y para coordinarlas con organizaciones del gobierno y otras agencias. En los libros de actas de la comunidad también aparecen los acuerdos de donación de terrenos familiares para la realización de obras para la comunidad como una escuela del PRONOEI (Programa No Escolarizado de Educación Inicial) a inicios de los 90.

Es en esta lógica que a finales de 1990 una familia donó parte de su parcela familiar para que funcionase en ella la Asociación Artesanal Tres Lagunas. La primera presidenta de la asociación fue elegida por haber hecho una buena gestión como presidenta del comité de mujeres o de Vaso de Leche (programa social creado por el Estado peruano a inicios de los 90 para distribuir lácteos y otros productos de primera necesidad destinados a infantes y gestionado por madres de familia). La conexión entre El Mirador y otras organizaciones comunales de mujeres como el Vaso de Leche se hace evidente no solo por la elección de ex-autoridades de estos comités como autoridades del Mirador (por lo menos los primeros años), sino porque además para algunos comuneros la asociación es como un "comité de mujeres", aunque con algunas diferencias importantes.

La formación de esta asociación es entonces doblemente significativa: por el hecho de que es la única organización con tierras y, sobre todo, porque es manejada por quienes tienen menos acceso a la tierra en los Andes: las mujeres (De la Cadena, 1992; Eguren et al., 2009). La segunda diferencia, como veremos más adelante, es que las mujeres del Mirador se han enfrentado abiertamente a las decisiones de la comunidad y han cuestionado algunas normas comunales, principalmente en lo referente a la participación de mujeres en la asamblea comunal.

En la actualidad, la tierra y el territorio de muchas comunidades campesinas del Perú se hallan en constante presión debido al interés del Estado por expropiar sus terrenos para favorecer la extracción de minerales o hidrocarburos, así como también de las empresas privadas que buscan expandir sus negocios, entre ellos el mercado de tierras (Burneo, 2012; Huamán, 2014; Díez, 2014). Como consecuencia de esto, la organización comunal de la tierra va cediendo paso a una organización que tiende al individualismo y a los intereses particulares orientados al mercado (Burneo, 2012; Huamán, 2014).

En el caso de Chinchero y en general en el Valle Sagrado de los Incas en Cusco, la presión sobre la tierra en la actualidad se da principalmente por el turismo. Si se conversa con pobladores de Urubamba, Calca o Pisac, por ejemplo, hay una percepción generalizada de que las tierras han terminado en posesión de foráneos y en especial de extranjeros (Tamayo y Zegarra, 2008). A pesar de la existencia de la actividad turística en el distrito de Chinchero, la gran mayoría de turistas no se quedan a dormir allí, pues por lo general se detienen solo unas horas en los alrededores de la Plaza de Armas de Chinchero donde se encuentran algunos monumentos prehispánicos o viviendas de artesanos.

Una guía me explicaba: "[los turistas] miran las ruinas, ven algunas exhibiciones de producción textil, quizás compran algo y se van. Es muy frío aquí para quedarse muchas horas". Es decir, que el rubro hotelero es muy bajo en comparación con otros lugares del Valle Sagrado, con lo cual el interés por adquirir tierras no es tan grande como en otras áreas. No obstante, esta situación cambió con el anuncio de la construcción del Aeropuerto Internacional en 2013. Desde entonces los precios 
de la tierra se han incrementado notablemente, debido a que (como el gobierno y la empresa constructora prometieron) se esperan oportunidades de trabajo y negocios relacionados con el turismo de forma directa (hoteles, agencias), o indirecta (restaurantes, tiendas, bazares, etc.) Sean ciertas o no estas predicciones y promesas de futuro, la especulación con los precios ha despertado el interés por los terrenos y con ello el deseo de adquirir títulos individuales de propiedad.

A pesar de que muchos en el distrito están entusiasmados con la idea de poder sacar rédito económico a sus terrenos "que antes no valían nada", la venta de tierras también genera ansiedad, sensaciones ambiguas y preocupaciones por el incremento de la delincuencia, la contaminación, las invasiones de tierras y la desaparición de la comunidad que este nuevo contexto genera o puede generar.

Cabe señalar que la venta de terrenos en la historia reciente de Chinchero data de los años 40 del siglo pasado (Núñez del Prado, 1949) y era algo común por lo menos hasta los 60 (Contreras, 1980), cuando ya la monetización de la economía comenzó a sentirse (Fabregat, 1970). Asimismo, a pesar de que la titulación de tierras individuales y el deseo de venta de tierras se expandió fuertemente desde mediados de los $90^{12}$ en toda la región del Cusco, la percepción general es que la titulación y especulación de precios en Chinchero ha sido generada por la construcción del nuevo aeropuerto, el factor clave que ha (re)incentivado el interés por la venta de tierras en todo el distrito. Para entender las repercusiones del turismo en el contexto de la privatización de tierras y aproximarnos a lo que El Mirador significa para las socias, relataré cómo recordaban sus inicios.

\section{El Mirador en la narrativa: turismo e historias de invasión}

Las socias recuerdan que esta colina no tenía nombre, era un lugar por donde pasaban para dirigirse a sus casas u ocasionalmente pastar sus animales. Habían visto gringos (turistas) en Chinchero, especialmente en el mercado dominical, pero - a excepción de un par de veces - nunca en la comunidad. Es más, recuerdan que de niñas sus padres solían amenazarlas: "Si no haces caso, el gringo te va a llevar, por eso, si veíamos algún gringo nos escapábamos” (Marta, 40 años). Esto cambió aproximadamente en 1998 (es decir, cuando el turismo en Cusco estaba en uno de sus picos más altos) cuando percibieron que los turistas subían a esta colina: "Cuando pastábamos a nuestros animales por este terreno, había gringos que se acercaban para tomar fotos. Un día un guía nos dijo: ¿por qué no les vendes tus ropas y tejidos? y ahí empezamos a vender" (Noemí, 45 años).

Además de la belleza del paisaje alrededor del Mirador, un factor clave para las socias y también para los guías de turismo para que esta colina fuera un atractivo turístico, fue su cercanía a la carretera principal que conecta el Cusco y el Valle Sagrado de los Incas. Como me decía un guía: "Cuesta muy poco tiempo a los operadores turísticos desviarse unos metros de la carretera para llegar a la colina”. Fue así como, poco a poco, operadores turísticos y pobladores empezaron a llamarla El Mirador.

12 La ley de tierras de 1991 dio inicio a una nueva etapa en la liberalización y privatización de tierras en las comunidades campesinas y nativas de Perú (Del Castillo, 1997) y un nuevo enfoque en la inserción de las comunidades campesinas en el mercado nacional y global. Como señala Malengreau (1992), a pesar de que la tierra constituye el marco principal de referencia para los campesinos, ya para inicios de los 90 estaba en marcha la privatización de tierras en los Andes peruanos. 
A pesar de que la mayoría de asociaciones artesanales en Chinchero y la región del Cusco están compuestas por mujeres, la historia del Mirador es peculiar porque está ligada a la historia de la defensa de la comunidad. Según las socias y los comuneros, la presencia cada vez mayor de turistas en El Mirador atrajo el interés de pobladores de la comunidad vecina de Wayraqpunco y de los experimentados vendedores del centro poblado de Chinchero. Se corrió la voz de que la comunidad estaba siendo "invadida", iniciándose así un nuevo capítulo en la historia de la comunidad. Según las socias, las heroínas de esta historia son ellas, porque fueron quienes tuvieron que subir a la colina a las tres de la mañana para "separar sitio" y evitar que los invasores vendiesen; y fueron ellas quienes presionaron a la comunidad para formar la asociación. Gracias a estas acciones las socias sostienen que expulsaron a todos los vendedores foráneos, con excepción de siete vendedoras de la comunidad vecina de Wayraqpunco, quienes finalmente se integraron en la asociación después de arduas negociaciones entre las socias y la comunidad.

Para las ex-autoridades, el principal actor en la defensa territorial fue la asamblea comunal (liderada por varones) puesto que hicieron los trámites necesarios para formalizar la asociación y "obligar" a los comuneros a ir a vender en El Mirador. Sea como fuere, estas narrativas muestran cómo los (re)inicios de la industria turística en Cusco provocaron situaciones ambiguas para las comunidades campesinas. Por un lado, esto representó una oportunidad de sacar algún beneficio del mercado turístico (del cual estas comunidades han estado y siguen estando marginadas) y, por otro, el turismo representó una amenaza a su territorio por la presión del mercado sobre la tierra. La historia de la comunidad es inseparable de la historia regional y nacional.

Historias de invasiones de tierras abundan en esta parte de los Andes, así como en el resto del Perú. En la historia escrita reciente de Chinchero, hay registros de invasiones de tierra desde mediados del siglo XX (Núñez del Prado, 1949). Y por lo menos desde los 70 (Contreras, 1980) y después a mediados de los 90 y en pleno inicio de la privatización de tierras, uno de los principales conflictos que las comunidades y sus asambleas tenían que tratar era el de las invasiones de tierras tanto familiares como comunales. La resolución de conflictos tanto internos (entre familias dentro de la comunidad) como externos (entre la comunidad y otras comunidades, individuos o entidades ${ }^{13}$ ) hasta el día de hoy, siempre pasa por la asamblea comunal. La formación de la asociación artesanal se enmarca en la función histórica de cuidar su territorio y resolver un conflicto como la invasión del Mirador.

Estas narrativas son una manera de construir memoria y posicionarse (frente a la historia oficial escrita) como agentes que defienden su territorio y se apropian de la historia. Esta apropiación va de la mano con acciones concretas que se materializan en la transformación que las mujeres hicieron en El Mirador.

\section{1. "De una colina a un mercado artesanal": la inscripción de las historias en las obras}

Las socias cuentan que cuando se formó la asociación en el año 2000, El Mirador apenas era una pequeña colina en cuya superficie las mujeres tendían una bolsa de

13 Hasta el día de hoy la comunidad sigue un proceso judicial por unos terrenos ocupados por una empresa nacional, lo que ha generado que algunos miembros de la comunidad se queden "sin comunidad". 
plástico para colocar sus artesanías y ofrecerlas a los turistas. Solo dos años después y como ellas dicen "gracias a las gestiones de la junta directiva" de la asociación, la municipalidad de Chinchero proporcionó maquinaria pesada para nivelar y ampliar el terreno del Mirador a casi el doble de tamaño. Estos primeros trabajos hicieron que surgieran las primeras negociaciones con la comunidad, debido entre otras cosas, a los requisitos de la asociación para aceptar nuevos miembros. Ellas recuerdan que alrededor del año 2007, la asociación ganó un concurso de proyectos de desarrollo cofinanciado por el Estado peruano y el Banco Mundial para la construcción de un mercado artesanal en el terreno del Mirador. La primera fase de este mercado incluyó la ampliación del terreno del Mirador y su división en dos partes: una para el estacionamiento de buses y la otra para la venta de artesanías. Asimismo, este proyecto trajo consigo la construcción de infraestructuras: puestos de venta individuales, un salón de reuniones, un depósito, un taller de trabajo y dos baños.

Las socias recuerdan que los guías turísticos se opusieron a la construcción de esta infraestructura, ya que según ellos se corría el riesgo de perjudicar la vista del paisaje natural que se contemplaba desde este lugar. Los guías advirtieron a las socias que de seguir con sus planes ellos dejarían de ir, por lo que el proyecto se detuvo durante casi dos años. Después de arduas negociaciones entre las socias y los operadores turísticos, se decidió cambiar la ubicación de los puestos de venta y el taller para que no "bloquearan" la vista del paisaje.

En sus relatos se percibe la influencia de los operadores turísticos en la organización y toma de decisiones de la asociación, lo que refleja los límites de su participación en el mercado turístico. En esta narrativa vemos también cómo una comunidad campesina interactúa no solo con agentes turísticos locales, sino también con agencias internacionales y globales como el Banco Mundial, para quienes proyectos de desarrollo como el mercado artesanal son importantes para promover y justificar sus políticas neoliberales en países como el Perú.

Las obras en El Mirador son la "escritura" de estas narrativas que da cuenta de las acciones e interacciones de las socias. El uso de las obras en sus narrativas solo se entiende si las relacionamos con el contexto regional e histórico.

\subsection{El Mirador es nuestra obra: legitimación del poder local}

En una ocasión, cuando las socias informaban sobre las críticas de otros comuneros por el costo de ingreso a la asociación, una de ellas dijo: "No es fácil traer obras, te tienes que mover, conversar con gente. Esa electricidad, los baños, son obra de mi gestión; hemos ido a la municipalidad, conversado con ingenieros, hablado con muchas personas. Es esfuerzo traer eso ${ }^{14 "}$ (Ester, 43 años).

14 Contreras (1980) describió que en Chinchero, durante los 70, la palabra trabajo refería al esfuerzo físico y al resultado del mismo, y era, por tanto, fuente de acceso a la tierra y prestigio social. Esta interpretación del trabajo era consecuencia de la internalización de la férrea competencia y de las normas del sistema de haciendas donde para garantizar el acceso a la tierra tenían que "mostrarse" laboriosos en la "chacra". Si bien la palabra trabajo también legitima el acceso a la tierra, en la actualidad las actividades más valoradas son aquellas relacionadas con actividades no agrícolas; profesiones como la de chófer, la venta de artesanías o tener "negocios". En este nuevo contexto, el esfuerzo físico no es necesariamente lo más valorado, pues si se prefieren otras profesiones es justamente porque estas no demandan tanto esfuerzo físico como la agricultura. El contacto con la cultura urbana a través de la migración, la educación de las nuevas generaciones (como ya adelantaba Contreras en 1980) y el asfaltado de la carretera Cusco-Chinchero en los 80 pueden explicar este cambio. En el nuevo contexto, 
Como esta cita sugiere, traer una obra a esta comunidad (y probablemente a otras) significa que una autoridad sabe establecer redes o "contactos" con municipalidades, instituciones estatales, programas de desarrollo gubernamentales y no gubernamentales; es decir, con el mundo urbano y mestizo. El dominio del castellano, tener "contactos" claves y tener conocimiento y experiencia sobre estas redes urbanas y burocráticas son cualidades altamente valoradas.

Las relaciones entre los comuneros y esa red, sin embargo, están fuertemente jerarquizadas y enclavadas en patrones de poder históricos. Como De la Cadena (1992) indica, la legitimación del poder en el ámbito comunal se ha realizado a través del acercamiento simbólico y efectivo con la esfera de poder regional. Por este motivo, la tierra era el principal marcador de estatus social, justamente porque permitía establecer relaciones de parentesco ritual o matrimonio con los mistis (mestizos y hacendados) y ascender étnicamente al grupo de poder regional ${ }^{15}$. Más tarde, la ciudad reemplaza a la tierra como marcador de estatus social, fuente de poder y ascenso étnico. El poder local ya no lo ostentaba el patriarca que acumulaba tierras, sino por ejemplo un carpintero, que acumulaba conocimiento y contactos urbanos.

En Pumapuqllo, además de este conocimiento urbano (y del mundo del desarro1lo), un legitimador de poder son las obras que, a pesar de los escándalos por denuncias de corrupción en todo el país, aún son una medida importante de la gestión de una autoridad. ¿Por qué? Una primera respuesta reside en los ingresos económicos que esta genera, no solo en las arcas de las municipalidades, sino también en los pobladores. En comunidades rurales de Chinchero, el trabajo en obras de construcción civil se ha convertido en una de las principales fuentes de ingreso debido al incremento exponencial de obras en las municipalidades generado por el canon gasífero ${ }^{16}$. Además, desde 2013, con el anuncio de la construcción del aeropuerto, existe un boom de la construcción de viviendas en toda la región. Trabajar en la construcción y, sobre todo, ser maestro de obras es altamente valorado por los varones del distrito. Como un comunero indica: "Prefiero trabajar en construcción. Trabajar en construcción no es cualquier cosa, se necesita conocimiento, saber de herramientas. Además es limpio, después de trabajar te limpias. En la chacra siempre paras sucio" (Miguel, 62 años).

Otra explicación del énfasis puesto en las obras me fue dada por las socias cuando en una reunión de la asociación, comentando acerca de los rumores de que la comunidad iba a demoler la infraestructura del Mirador para poder ampliar una pista, dijeron: "Esto no se puede desatar fácil. ¿Cómo vamos a desatar lo que ha construido el Estado?", a lo que otra socia agregó: "La cocina (una habitación en El Mirador) la ha construido el Estado [peruano]; esto no lo podemos desatar porque es del Estado." (Cintia, 32 años).

A pesar de que parte de la construcción del mercado artesanal fue hecha por instituciones no gubernamentales, las obras en ocasiones de negociación, por ejemplo, dan cuenta de una fuente de poder superior: el Estado. Esto tiene que ver con las prácticas de la comunidad, donde una de las funciones de la asamblea comunal es establecer redes con el Estado a través de obras. El hecho de arrogarse esta acción

lo que legitima la acción de los comuneros y autoridades son los contactos urbanos y el manejo del lenguaje técnico del desarrollo, cuya forma material son las obras.

15 Un caso similar es relatado por Matos (1957) en la isla de Taquile, en el lago Titicaca, donde los comuneros que tenían éxito en recuperar y acumular tierras adquirían gradualmente el estatus de mistis.

16 La región del Cusco alberga el yacimiento de Gas más importante de Perú: Camisea. 
por parte de las socias, denota una forma de legitimarse políticamente. Esta legitimación se explica además en algo que han señalado otros estudios: la nación peruana es un importante referente de pertenencia. Esto tiene que ver con el hecho de que la construcción de infraestructuras civiles desde, por lo menos, inicios del siglo XX ha sido largamente promovida por el estado peruano como motor de industrialización, progreso, modernización y creación de ciudadanía (Drinot, 2016). Como atestigüé en la descripción de la huelga que abre este texto, si bien el objetivo de la plataforma de lucha era exigir la construcción del aeropuerto y el Gasoducto Sur, las reivindicaciones también eran contra el centralismo y el monopolio de la economía. Las personas pedían ser parte de ese crecimiento económico y "desarrollo" peruano del cual tanto hablan los funcionarios del Estado. Pedían los mismos derechos (y obras) que otros ciudadanos que viven en Cusco o Lima. Como indicaba un comunero en la huelga: "El centralismo de Lima no quiere el aeropuerto aquí, no quieren nuestro desarrollo" (Aurelio 43 años).

El reclamo de acceso a la educación formal es quizá el ejemplo más claro de la demanda de las comunidades por una plena ciudadanía. Es por esto que no sorprende que las comunidades de Chinchero y los Andes hayan luchado por la construcción de escuelas y demandado profesores que enseñen a leer y escribir en español (García, 2008; Sandoval y Agüero, 2013). Para los pobladores, adquirir el español es una manera de dejar de ser objeto de estudio y ser agentes de su propio destino, ya que "se apropian del lenguaje del opresor para resistir la opresión" (García, 2008: 146) ${ }^{17}$. Las obras en este contexto son la forma en que las poblaciones a nivel local (re) interpretan y buscan apoderarse de ese lenguaje oficial, de esos símbolos de poder, modernidad, progreso, ciudadanía, "inscritos" en las obras. Las socias hacen uso de estas imágenes para legitimar su poder en la comunidad, reinterpretándolas en el lenguaje local.

\subsection{EI Mirador y los usos locales de la tierra}

Un segundo punto para entender los significados de las obras en El Mirador es su relación con los derechos de propiedad y los usos locales de la tierra. Como examinamos en la primera parte, en la comunidad nunca antes se había otorgado un terreno a un comité comunal. ¿Qué derechos sobre la tierra les entregarían entonces a las socias? Como dijimos al principio, la principal forma de distribución de la tierra en la comunidad es la parcela familiar, de la cual se puede hacer uso pleno pudiendo heredarla o arrendarla sin intervención de la comunidad. Sin embargo, si se quiere transferir la tierra incluso a otro comunero se debe consultar a la comunidad. Cuando surgió el reclamo de la familia, surgió el problema de cómo proceder y solucionar este conflicto por la tierra. La familia y las socias buscaron la solución tratando de buscar un precio justo por la transferencia interna del terreno. Al no llegar a un acuerdo y siguiendo la lógica local, buscaron la intervención de la asamblea comunal a través de su presidente. Este, sin embargo, les dijo que "ese era un problema

17 Para Canessa (2012), la educación formal en los Andes bolivianos es una manera nueva de colonización, ya que es a través de las clases y textos escolares que los indígenas acceden a una ciudadanía que valora como superior la cultura urbana y mestiza. En el caso peruano se da una situación semejante, a través de la educación formal, la migración y el éxito económico, personas nacidas "indígenas" se volvieron mestizas (o indígenas mestizos) (De la Cadena, 2000). 
entre la comunidad y las socias", con lo cual desconocía por un momento al Mirador como un terreno comunal, ya que el precio de la trasferencia de parcelas familiares se espera que sea manejado entre los comuneros, pudiendo la comunidad avalar el acuerdo en asamblea.

Después de esta respuesta y ante la posibilidad de perder El Mirador, las socias lograron persuadir a la asamblea de que el terreno se considerase comunal, pero solo para evitar tener que reponer ellas mismas el terreno. Una vez reconocido El Mirador como terreno comunal, su objetivo fue legitimar la posesión o el derecho de usufructo recurriendo a los principios de uso de la comunidad. Como expliqué en la primera parte, en la comunidad de Pumapuqllo el requisito indispensable para ser comunero y tener derecho a una parcela es tener y hacer uso del terreno. Aunque no está en los estatutos, el tener una casa o alguna construcción en el terreno afianza la idea de que uno lo está usando. La relación entre el trabajo, la construcción o modificación del terreno y el derecho de usufructo y propiedad ha sido señalado en otros lugares (Márquez, 2013; Montesinos, 2013). Las obras en El Mirador representan el valor del trabajo y reafirman su posesión siguiendo un uso local. La modificación física del Mirador y sus obras es el "titulo" de propiedad del Mirador.

El hecho de que sean mujeres las usufructuarias de este terreno comunal les impone mayores retos y les obliga a recurrir a otros significados de las obras, más allá de la comunidad, como vimos anteriormente cuando afirmaban que las obras "son del Estado". Lo primordial para poseer un terreno es, sin embargo, "hacerlo respetar", lo que implica cumplir con los deberes de un comunero: hacer faenas y asistir a las asambleas comunales. Es en la asamblea comunal donde se decide la condición de socio o la distribución de terrenos y es por eso que cuando hay litigios los nuevos y viejos comuneros se hacen presentes en la asamblea. Si bien es cierto que las obras en El Mirador favorecen la posición de las socias, ellas necesitan "hacer respetar" El Mirador cumpliendo sus derechos y obligaciones como comuneras. Pero hay un problema, y es que a pesar del cumplimiento de sus obligaciones con la comunidad - como por ejemplo pagar una cuota cada año por el aniversario de la comunidad - no pueden asistir a las reuniones comunales por ser mujeres. Como veremos a continuación, las relaciones de género no solo han tenido un rol primordial en estas negociaciones, sino que ellas mismas han sido afectadas en el proceso.

\section{El papel del género en las disputas por el Mirador}

\section{1. "Las mujeres despiertas": participación de mujeres en la asamblea comunal}

En muchas ocasiones escuché quejarse a las mujeres de la comunidad porque tenían prohibido asistir a las asambleas comunales, que pueden ser de dos tipos: ordinarias y extraordinarias. Las ordinarias se dan cada mes y las extraordinarias cuando se presenta algún asunto que requiere inmediata atención. Dependiendo de la importancia del asunto, por lo general, las mujeres pueden participar (firmando asistencia) en las extraordinarias, en el caso de que la convocatoria haya sido tan rápida que no haya dado tiempo para que los varones pidan permiso o consigan reemplazo en sus lugares de trabajo. Por el contrario, las mujeres no pueden firmar en las reuniones ordinarias, donde, generalmente, se toman las decisiones más importantes para la comunidad: titulación de tierras, incorporación de nuevos comuneros, construcción de 
alguna obra o la creación de alguna organización comunal. Por tanto, si bien no está prohibida su asistencia, esta no es tomada en cuenta (firmada) ni deseada. La razón, según refieren las autoridades de la comunidad, es que en las normas y estatutos está escrito que solo puede firmar el titular de un terreno, quien es el jefe de familia, es decir, un varón.

En la mayoría de comunidades del distrito, la participación de las mujeres en las asambleas comunales ordinarias es menor que la de los varones. En este escenario, no es raro que las principales autoridades de la comunidad (la junta directiva) sean varones, a excepción de algunos puestos como el de vocal o el de tesorero, cargos que en los últimos años vienen siendo ocupados ocasionalmente por mujeres, con la idea de que "son más responsables que los varones"; una idea muy difundida tanto en las comunidades como en las instituciones del gobierno, programas de desarrollo y ONGs en la región del $\mathrm{Cusco}^{18}$.

La exclusión de las mujeres de las asambleas comunales y la preferencia por autoridades masculinas podría ser interpretada como consecuencia de una separación entre lo público (relacionado con la política) y lo privado (relacionado con lo doméstico, el cuidado de la casa y los hijos). Dicha separación, sin embargo, ha sido criticada por varios autores ya que en las prácticas cotidianas las fronteras entre lo público y lo privado son difusas: lo doméstico influye en lo público y viceversa. A pesar de su exclusión de la esfera política "oficial", las mujeres hacen uso de otro tipo de poder, uno no oficial (Lamphere, 2005). Por ejemplo, Harvey (1989) encuentra que en una comunidad de la región del Cusco, las únicas reuniones a las que las mujeres podían asistir se consideraban "informales" y de menor importancia, porque se tomaban acuerdos relevantes solo para ellas. Por otro lado, las mujeres encontraban siempre maneras (a través de sus esposos o en las mismas reuniones informales) de presionar a la comunidad para que tomara decisiones que consideraban de su interés.

Como Lamphere (2005) afirma, en muchas culturas el espacio doméstico es a la vez reproductivo, económico y político. Podemos decir lo mismo del Mirador, pues aquí las mujeres venden y hacen sus artesanías, cuidan a sus hijos menores y toman decisiones para defender el Mirador a través de vías "formales" e "informales". Por ejemplo, antes de la asamblea comunal en la que se discutió el valor del terreno, las socias hablaron informalmente (encuentros en espacios y tiempos no consensuados) con las esposas de las autoridades de la comunidad para que persuadieran a sus esposos para aceptar tratar el tema del terreno en una reunión comunal, cosa que lograron con éxito. Además, las reuniones de "organizaciones de mujeres" como la de seguridad alimentaria son espacios para concertar y diseñar estrategias políticas. Las mujeres son agentes políticos e influyen en la toma de decisiones de la comunidad. Sin embargo, aunque no están excluidas del poder, las mujeres de la comunidad, y las socias, en particular, encuentran que su exclusión de las asambleas es una desventaja importante a la hora de defender sus intereses. El poder informal o indirecto no es suficiente.

Esto tiene que ver, como expliqué antes, con que la asamblea comunal es considerada el principal espacio político e intermediario entre la comunidad y el Estado. La exclusión de mujeres de espacios formales de la política es algo muy común en

18 Es común que en los programas de ayuda y lucha contra la pobreza, como JUNTOS, el dinero sea entregado principalmente a la madre, ya que se piensa que ella es más responsable que el esposo. Esta política es muy común en este tipo de programas a nivel mundial (ver Escobar, 2011). 
otros lugares. Haciendo un análisis histórico y etnográfico, Segato (2014) alega que la colonización de América y el discurso igualitario de la modernidad ha puesto a los varones como los intermediarios entre sus comunidades y la administración colonial / estatal y urbana. Este hecho ha significado una "superinflación" del poder de los varones generando un binarismo "abisal" entre lo público y lo privado.

No tengo información de la comunidad antes y durante la colonia, pero el libro de actas de la comunidad desde hace más de cincuenta años y el testimonio de algunas personas, indican que la asamblea de la comunidad y su junta directiva fue desplazando en poder a las autoridades tradicionales denominadas varayoq (algo común en otras partes de la región y los Andes). Asimismo, estas fuentes indican que el Estado, ONGs y otras instituciones han tendido a convocar mayormente a varones para pactar diferentes proyectos. Los proyectos de desarrollo asumen de antemano (como en el caso de las ceramistas en Pisaq) una separación estricta de roles entre varones y mujeres, creando proyectos exclusivamente para varones o para mujeres. Los proyectos dirigidos a mujeres están relacionados con tareas domésticas: el cuidado de niños (como el Vaso de Leche o el Club de Madres) o el cuidado de la casa, cocina, huertas y crianza de animales menores (como el proyecto de Seguridad Alimentaria).

En los últimos años, en todo el distrito hay proyectos gubernamentales y no gubernamentales dirigidos a la mejora del tejido y la artesanía cuyas principales beneficiarias son las mujeres. Por otro lado, los proyectos dirigidos a varones están relacionados con actividades mercantiles como la crianza de animales mayores, construcción y mejoramiento de tecnología agrícola. Temas que afectan a toda la comunidad como la elaboración de diagnósticos de la comunidad donde se incluía la historia, el conocimiento del territorio y áreas agrícolas, la titulación de tierras y coordinación con los ingenieros encargados de elaborar los mapas de la comunidad, fueron realizadas en la asamblea comunal, con presencia mayoritaria de varones. Este binarismo y la lucha de las socias por participar en la asamblea han afectado las relaciones de género de la comunidad y la identidad de las mujeres de la asociación, a veces, de manera contradictoria.

Las mujeres de la asociación han sido reconocidas en toda la comunidad no solo por ser quienes demandan asistir a las reuniones comunales, sino porque intentan dar sus opiniones en las asambleas comunales (firmen o no la asistencia). Además, cuando la asociación ha sido convocada a exponer, las socias son firmes en la defensa del Mirador, alzando muchas veces la voz. Es por esta notoriedad que las socias han sido estigmatizadas con el sobrenombre de simi sapas (boconas), ya que para algunos comuneros "hacen mucha bulla, hablan en desorden, son desorganizadas" (Edgar, 37 años). A pesar de que en las asambleas comunales los varones también conversan y se ríen mientras alguna autoridad habla, la percepción general es que son las mujeres las bulliciosas. Esta percepción es tal, que para algunos comuneros la presencia de mujeres es banal, porque "no saben dar buenas opiniones, hablan en desorden, se duermen o tejen ipor gusto van a la asamblea!" (Roberto, 47 años). Al calificarlas de boconas no solo están subrayando la transgresión de las normas de la comunidad y la ruptura de los ideales tradicionales de femineidad, sino que además es una manera de trivializar sus reclamos y descalificarlas como agentes políticos.

Es interesante notar que procesos similares se han dado en otros contextos, como es el caso de la participación política de las vendedoras de mercado en Bolivia y Cusco, quienes, a pesar de convertirse en protagonistas de las huelgas generales y movimientos sociales, fueron desestimadas como agentes políticos calificándolas 
entre otras cosas de "escandalosas" (Seligmann, 1989; Velásquez et al., 1996; De la Cadena, 2000; Weismantel, 2001). Irónicamente, lejos de ser un insulto, estas mujeres reinterpretaron las acciones "escandalosas" en estas protestas como parte esencial de su estrategia política para defender sus derechos. Es así que las acciones escandalosas se han convertido en una virtud cívica y en una cualidad: "mujeres que se hacen respetar", es la manera como ellas califican y valoran estas acciones políticas (De la Cadena, 2000).

Similar al caso de las vendedoras de mercado, la mayoría de socias sienten orgullo de alzar la voz porque es la manera de defender sus intereses. Para ellas, y también para otros miembros de la comunidad, las socias no son "boconas", sino "despiertas", porque ahora "ya no se quedan calladas, se defienden, se organizan" (Ernesto, 40 años). Así, el hablar en voz alta o exigir su presencia en las asambleas es visto como algo esencial para "hacer respetar" El Mirador, es decir, tener derecho a usufructo siguiendo las normas locales de la tierra.

A partir de la defensa del Mirador, las socias son reconocidas por la comunidad como líderes comunales y esto les ha llevado a ocupar cargos principales como el de tesorera, junta del Vaso de Leche o de Seguridad Alimentaria. Algunas incluso han incursionado en política partidaria dentro del distrito. Al mismo tiempo que las socias son llamadas boconas o despiertas, se las compara con el resto de mujeres de la comunidad, que son percibidas por algunos como "en pañales", es decir, que no están en la asociación, que no saben "defenderse" y no tienen ningún "negocio".

Las acciones de las socias en El Mirador están agregando nuevas terminologías y maneras de percibir la femineidad en la comunidad: mujeres despiertas y mujeres en pañales. Si bien es cierto que estos sobrenombres no son de uso general, su existencia da cuenta de cómo el orden de género se reproduce en el día a día tomando prácticas locales y no tan locales. El género se (re)produce y negocia constantemente. En la siguiente parte veremos que además de estos sobrenombres, se suma la terminología de los programas de desarrollo para diferenciar a las socias del resto de mujeres de la comunidad.

\subsection{Mujeres organizadas y warmichas: construcciones de género global y local}

Una palabra en castellano que se escucha frecuentemente en las narrativas sobre la defensa del mirador es organización. "Falta de organización" es la explicación que usan cuando sienten que han fracasado en alguna empresa como ganar algún concurso de tejido o si las ventas no andan bien. "Buena organización" aparece cuando relatan los éxitos de la asociación, como el haber conseguido financiamiento para construir el mercado artesanal o haber logrado administrar El Mirador. Esta manera de entender "organización" ocurre en otras partes del Cusco y del continente (Escobar, 2011). Cusco es una de las regiones de Perú con mayor presencia de programas de desarrollo y donde muchas ONGs se han convertido no solo en una importante fuente de empleo, sino también en legítimos actores políticos que influyen y dinamizan la vida rural (Asensio, 2016). En este contexto, no es de extrañar que la palabra organización sea parte del vocabulario diario, pero como veremos en el siguiente caso, esta palabra es (re)interpretada dentro del contexto histórico y social andino.

Como en tantas ocasiones, las socias recuerdan la vez que la asociación fue presionada por las autoridades comunales para pagar una cuota mensual por vender en El Mirador y para que permitiesen la inscripción de nuevos socios. Recuerdan ade- 
más que, al poco tiempo de haber aceptado nuevas socias, estas se retiraron porque no vendían como esperaban y, sobre todo, porque les pareció que les quitaba mucha energía y tiempo. El problema según ellas era que: "No sabían organizarse como nosotras, que nos levantamos temprano, cocinamos, volvemos y trabajamos en la chacra. También sabemos venir limpiecitas ¿acaso sucio vas a ir a vender allá arriba? ¡Qué dirían los turistas! Es cuestión de organizarse nomás” (Marta, 34 años). El referente inmediato de esta palabra se halla en las interacciones que tienen los comuneros con diferentes proyectos sociales y de desarrollo, tanto gubernamentales como no gubernamentales ${ }^{19}$. A nivel local, la palabra organización va más allá de llevar las cuentas o asistir a las asambleas y cumplir los acuerdos tomados en la asociación, la comunidad o Seguridad Alimentaria, es también saber organizar los quehaceres de la casa (limpiar, cocinar) e incluso el propio cuerpo (estar limpia). Sin embargo, para que esta palabra obtuviera el valor que tiene era necesario primero que la actividad de venta de artesanía fuera aceptada como una actividad femenina.

Según las socias, al principio sus esposos no querían que fueran a vender artesanía: "Mi esposo me decía: ¿para qué vas a ir allí? A estar sentada engañando a los gringos (turistas) vendiendo tus trapos" (Marta, 30 años). Algunas socias recuerdan haber vendido "a ocultas" en El Mirador, es decir, sin que sus parejas o familia se enterasen. Pero una vez que El Mirador se volvió rentable (los primeros años incrementaron sus ganancias en más de un 500\%), la actitud de sus esposos cambió. Así lo recordaba una socia en 2006: "Ahora mi esposo me dice: ¡anda, apúrate a vender al Mirador! incluso se queda ayudando a alistar a mi hijo" (Noemí, 30 años). Las socias han luchado porque la actividad de venta de artesanía sea aceptada como una actividad legítima. Además de enfatizar las ganancias de los primeros años, las socias hacen referencia también a otros centros artesanales de mujeres en toda la región del Cusco, donde la venta y producción de artesanía es reconocida como un trabajo.

Hoy en día muchas personas de la comunidad consideran El Mirador como un trabajo, o como ellos dicen, un "negocio". La preocupación en que sea reconocido como tal guarda relación con los ideales de femineidad más recientes en los Andes peruanos. En las diferentes entrevistas y conversaciones con los comuneros y pobladores del distrito, muchos resaltaban que una buena mujer o warmicha es aquella que además de realizar sus quehaceres de la casa, sabe traer dinero a la familia, tener un negocio. En la actualidad, este ideal de femineidad se ve tanto en comunidades rurales como en algunos grupos urbanos, como es el caso de las vendedoras del Mercado de San Pedro (Velásquez et al., 1996; De la Cadena, 2000; Weismantel, 2001).

Tradicionalmente, una manera de generar estos ingresos es por medio de un negocio propio: un bazar, venta de chicha (bebida andina a base de maíz), o comida. Sin embargo, después del surgimiento del Mirador, el vender y sobre todo tejer para vender a turistas se ha convertido en una cualidad de una warmicha o buena mujer. Si bien es cierto que el ideal de warmicha para las nuevas generaciones es sobre todo tener una profesión ( $\mathrm{y}$ con ello dejar la agricultura ${ }^{20}$ ), en la comunidad el combinar labores del hogar con el negocio es altamente valorado. Una buena mujer realiza

19 Aunque en el presente artículo no se hace una revisión etimológica de esta palabra, es importante recordar su relación con las políticas neoliberales de desarrollo y de alivio a la pobreza, que son promovidas, entre otras, por entidades como el Banco Mundial y el Banco Interamericano de Finanzas, y que son aplicadas por los gobiernos en proyectos conocidos ahora como de Desarrollo Rural.

20 Como en muchos lugares de los Andes el acceso a la educación formal es el máximo deseo de padres e hijos (García, 2008; Sandoval y Agüero, 2013). En la comunidad, como se percibe el deseo de educación ha afectado 
labores productivas y reproductivas, "se organiza" para poder vender en El Mirador y cuidar su casa al mismo tiempo. Una buena mujer ahora es una mujer organizada, tejedora, que tiene negocio y es buena madre ${ }^{21}$. En este sentido: ¿hasta qué punto las socias desafían o refuerzan las construcciones de género de la comunidad?

\section{Discusión: agencia y división del trabajo}

El caso del Mirador nos hace pensar en las posibilidades y límites que tienen los comuneros y las mujeres para producir efectos en su entorno. Como vimos en el marco teórico, la capacidad de actuar y generar cambios en el entorno (agencia) es inseparable de las estructuras sociales. En este sentido, como hemos visto, las mujeres de la asociación El Mirador han desafiado las normas internas de la comunidad al pedir voz y voto en la asamblea comunal, pero lo han hecho desde su posición de mujeres. Las normas comunales sobre acceso a la tierra y participación en asambleas siguen concepciones de género locales y no locales. Las mujeres de la asociación - consciente o inconscientemente - se han tenido que armar de los símbolos que legitiman una autoridad política: obras y organización. Sin embargo, para que dicha legitimación funcione tenían que ser primero buenas mujeres: warmichas. Así, las socias se mueven como agentes políticos en la comunidad, pero lo hacen siguiendo normas locales y no locales de femineidad. El sistema de género, al mismo tiempo que las subordina, les da las herramientas para su agencia. Es decir, su capacidad de acción, de influir en su entorno, se da dentro de las fronteras que pone el mismo sistema de género: las mujeres líderes o "despiertas" pueden tener accionar político solo si han demostrado ser warmichas. El reclamo de participación en las asambleas comunales está relacionado con su labor de buenas mujeres como administradoras de la economía familiar (no pagan multa por inasistencia), es decir, que esta acción estaría "incluida" o sería parte de un proyecto no de ellas, sino de su familia, y por ende, del sistema basado en la familia. De igual manera, su participación en cargos políticos en la comunidad (como el de tesorera) o su buena labor en organizar sus diferentes comités, responderían a proyectos más allá de ellas mismas: la comunidad, la familia o el Estado peruano. En otras palabras, más que desafiar, ellas están reforzando las estructuras de género.

Sin embargo, aun dentro de los límites puestos por el sistema, sostengo que las actividades de las socias las ha llevado a cuestionar la posición subordinada más visible para las mujeres —el no participar en asambleas comunales - lo que ha ocasionado a su vez que surja una reflexión sobre su posición como mujeres en general. No digo que antes no hubiese ninguna reflexión, pero con El Mirador se abrió una nueva posibilidad de ser agentes políticos y con ello dirigir su atención al sistema que las subordina. Como dice Connell (1987), a través de las acciones es posible que la estructura social pase a ser objeto de las prácticas y pueda ser desafiada.

Las socias asimismo experimentan y reflexionan sobre el lugar que ocupan respecto al turismo y la artesanía. Si bien las ganancias en El Mirador fueron grandes

también a los ideales de género, ya que los padres prefieren que sus hijas sean profesionales a que cocinen o cuiden su hogar.

21 Para un caso similar en el contexto de la participación de las mujeres en movimientos sociales en América Latina, ver la discusión sobre el concepto de supermadre que hace Nina Laurie (2011) 
al inicio, en los primeros años, estas decayeron considerablemente debido al incremento de la competencia de más asociaciones de artesanas en todo el distrito. Como atestigüé en el trabajo de campo, incluso en temporada alta (donde hay mayor flujo turístico) hay días donde las socias no venden nada a pesar de que los turistas suben al Mirador ${ }^{22}$. Como dice una socia: "Vienen turistas, se toman fotos, a veces entran al baño, pero no compran. Los guías no sé qué les dicen y les llevan a otras casas [asociaciones artesanales]" (Mirta, 34 años). "Lo que pasa es que los guías y agencias de turismo ya tienen hablado con otras casas en Chinchero, donde les dan hasta $20 \%$ [de las ventas]. Hasta les dan comida, chicha. Ya no se puede así" (Julia, 40 años). Esta situación es común en muchas partes de los Andes (Zorn, 2004; Escobar, 2012) donde la posición de intermediarios entre los turistas y los vendedores, pone a los guías en una posición ventajosa respecto a los vendedores. Cabe resaltar, sin embargo, que esta práctica no es exclusiva del turismo, y que está relacionado con el modelo estructural del turismo en el país, donde muchos guías están en desventaja a la hora de negociar sus condiciones de trabajo con sus empleadores ${ }^{23}$.

Las socias han experimentado cómo su posición social se ve afectada por procesos macroeconómicos como el surgimiento del turismo o la privatización de la tierra. La baja venta ha hecho que en algunos casos los esposos las recriminen: "Nos dicen: "están sentadas en el sol y no venden nada"' (Antonio, 45 años). Incluso en el contexto actual del boom de la construcción algunas socias han dejado de ir al Mirador ya que ahora sus esposos están trabajando cada vez más en construcción y no tienen tiempo para realizar labores domésticas. Estos cambios macroeconómicos tienen efectos diferenciados para las mujeres. Ellas son conscientes de que su futuro no depende exclusivamente de ellas: "No sabemos qué pasará con las artesanías. Hay muchas casas, tenemos que contactar agencias de turismo o movernos. Pero es difícil. Quizás ya no vendemos artesanías. Quizás este mirador se convierta en otra cosa, en una feria o algo, porque quizás con el aeropuerto ya no vienen turistas por el ruido. O quizás sí, no sabemos. Pero algo se hará aquí. Por eso no suelto esto [El Mirador] aunque sea mis hijos recibirán" (Sara, 41 años).

Estas reflexiones de las socias sobre su ubicación en la comunidad y la región tienen relación con la división del trabajo a escala global. Como adelantamos en el marco conceptual, en el sistema-mundo moderno/capitalista/eurocentrado y global la división del trabajo es engenerizada, racializada y "geográficamente diferenciada" (Lugones, 2008:80). Este sistema ha posicionado a unos (mayormente varones blancos) como trabajadores asalariados y a otros (mayormente mujeres y colonizados) como sirvientes, esclavos (o mal remunerados), es decir, su trabajo no es trabajo, sino parte de su condición social. Este sistema no podría mantenerse sin esta división (Curiel, 2010; Alvarado, 2016). De igual manera, el turismo y la artesanía, en general, son engenderizadas y racializadas: las mujeres campesinas tienen el rol principal de representar lo auténtico tradicional.

22 Esto guarda relación con la complementariedad entre el trabajo artesanal y la actividad agrícola, donde la temporada de lluvias que requiere más trabajo en la agricultura coincide con la temporada baja del turismo (Contreras, 1982). En el centro poblado de Chinchero, sin embargo, la actividad artesanal es para algunas familias la principal fuente de ingreso (Wollum, 2014).

23. Algunos guías indicaron que cada vez más empresas turísticas incluyen estas comisiones como parte del pago por sus servicios de guiado. Explican que debido a la saturación de la oferta en este oficio, muchas veces aceptan salarios bajos, viéndose obligados a completar sus ingresos con dichas comisiones y que, generalmente, se comparten con los conductores de los buses de transporte. 
Pero al realizar estas actividades en el turismo ellas han reinterpretado sus trajes como uniformes, sus representaciones del turismo como trabajo y el saber tejer y vender como cualidades de warmichas. Han invertido dinero y tiempo en hacer presentaciones para los turistas, como una socia recuerda: "Los guías nos decían ¿¿por qué no hacen una demostración de cómo hacen sus tejidos? eso les gusta a los turistas' así que viendo, viendo cómo hacen eso en Chinchero hemos hecho aquí también" (Marta, 45 años). Sin embargo, dejaron de hacerlo porque no les "salía a cuenta": "Incluso bailábamos y hacíamos bonito, pero era gasto también. Esos trajes cuestan. La lana y tejido para la demostración también, al final ni siquiera compraban, solo sacaban fotos y se iban" (Ester, 44 años). Como esta cita sugiere, el trabajo de las socias en hacer demostraciones, tejer cuando vienen los turistas, invitar a sus productos agrícolas a los guías y turistas, traer y mantener a un par de alpacas que están ahí para que los turistas se tomen fotos, no es considerado trabajo para las empresas o el Estado, sino parte de su condición de artesanas; como algo que deben hacer por vender sus artesanías. Estas representaciones de trajes típicos, tejidos y llamas, paisajes, creación de atractivos turísticos como El Mirador, "que no representan costo extra" a las empresas turísticas, representa el trabajo no asalariado del turismo en el actual modelo turístico de la región del Cusco.

Las socias, sin embargo, al mismo tiempo que critican la competencia desigual en el turismo continúan luchando por tener un lugar en el modelo actual. Ellas luchan por tener acceso a esos beneficios económicos del turismo del que tanto hablan representantes del Estado y personas a lo largo del Valle Sagrado de los Incas: "Seguiremos haciendo algo, algo habrá, no podemos quedarnos sentadas" (Cristina, 35 años).

\section{Reflexiones finales}

El valor del Mirador rebasa las nociones puramente económicas, por eso la negación a ser intercambiado por otro terreno o por dinero. No es solo un espacio donde conseguir un ingreso extra durante la temporada alta del turismo, sino que es un lugar lleno de significados: de memorias, luchas por la defensa de la comunidad y la asociación, de interacciones con el Estado y donde se aprende a tejer, a ser mujeres organizadas y warmichas.

Las modificaciones físicas del Mirador y las negociaciones por su control con la comunidad han traído consigo reflexiones sobre la posición que las socias ocupan en sus familias, en la comunidad y en la actividad turística. En relación con la comunidad, cabe resaltar que tanto varones como mujeres de la comunidad expresaron la importancia de la asamblea comunal en proteger sus derechos. Por esa razón, uno de sus principales temores con la privatización de tierras y la construcción del aeropuerto es que la asamblea comunal pierda su poder o la comunidad como institución desaparezca. Como un comunero explica: "La comunidad desaparecerá si todos tienen títulos y hay gente extraña ¿cómo la comunidad va a obligar a asistir y hacer faenas?" (Juan, 38 años).

El deseo y esfuerzos de las socias de tener una mayor presencia en la política oficial de la comunidad deben entenderse a la luz del deseo de la continuidad de la asamblea comunal. Esto guarda relación con lo que sugieren Segato (2014), Paredes 
(2013) y Rivera (2010), para quienes la transformación de la situación de las mujeres debe apoyarse en la organización colectiva o comunal (no individual), donde varones y mujeres, y las esferas domésticas y públicas sean ambas entidades ontológicamente completas y provistas de poder.

Quizás el camino para esta transformación social en clave colectiva ya lo están haciendo y recorriendo las socias del Mirador. Ellas están organizadas colectivamente en la asociación que, si bien es parte de la comunidad, ha tenido por mucho tiempo autonomía y capacidad de acción convirtiéndose en un agente político comunal importante. A pesar del binarismo de los programas de desarrollo y las ocasionales fricciones con la asamblea, la asociación no se contrapone a la comunidad. A través de la asociación, ellas han formado un bloque para defender sus intereses colectivos tanto dentro como fuera de la comunidad. Hay que resaltar que esta organización colectiva se mantiene porque cuenta con marcadores de poder local: tierra y obras. El contexto de la construcción del aeropuerto y la titulación de tierras presenta un nuevo reto; es el inicio de otras narrativas y prácticas donde ellas lucharán otra vez por ser agentes y donde no faltarán historias de heroínas en la defensa del Mirador, la comunidad y, seguramente, de su posición como mujeres.

\section{Referencias bibliográficas}

Alvarado, Mariana (2016). "Epistemologías feministas latinoamericanas: un cruce en el camino junto-a-otras pero no-junto-a-todas". Revista de Ciencias Sociales y Humanidades, Vol. 1 (3): 9-32.

Asensio, Raúl H. (2016). Los nuevos Incas: La economía política del desarrollo rural andino en Quispicanchi (2000-2010). Lima: Instituto de Estudios Peruanos.

Babb, Florence E. (2010). The Tourism Encounter: Fashioning Latin American Nations and Histories. California: Stanford University Press.

Babb, Florence E. (2012). "Theorizing Gender, Race, and Cultural Tourism in Latin America A View from Peru and Mexico". Latin America Perspectives, Issue 187, Vol. 39, (6): 3650.

Burneo, María Luisa (2012). "Elementos para volver a pensar lo comunal: nuevas formas de acceso a la tierra y presión sobre el recurso en las comunidades campesinas de Colán y Catacaos". ANTHROPOLOGICA/AÑO XXXI, N. ${ }^{\circ} 31$, pp. 15-41.

CBC (1997). Taller regional Comunidades campesinas y saneamiento legal en el contexto de la nueva ley de tierras 12 y 13 de agosto. Cusco: Casa Campesina, CBC Cepes.

Canessa, Andrew (2012). Intimate Indigeneities: Race, Sex, and History in the Small Spaces of Andean Life. Durham \& London: Duke University Press.

Connell, Robert William

- (1987). Gender and Power. Cambridge: Polity Press.

- (2002). Gender. Cambridge: Polity Press.

Contreras Hernández, Jesús

- (1980). "La valoración del trabajo en una comunidad campesina de la sierra peruana". Boletín americanista. $\mathrm{N}^{\circ}$. 30. págs. 41-68.

- (1982). "La producción artesanal en los Andes peruanos: del valor de uso al valor de cambio". Boletín americanista, $\mathrm{N}^{\circ} .32$, págs. 101-114

Curtis, D. (2009). Pleasures and Perils. Girls' Sexuality in a Caribbean Consumer Culture. Rutgers University Press. 
Curiel, Ochy (2010). “Género, raza, sexualidad debates contemporáneos". Conferencia presentada en la Universidad Autónoma Metropolitana - Xochimilco Disponible en: $<$ http://www.urosario.edu.co/urosario_files/lf/lfld1951-0f7e-43ff-819f-dd05e5fed03c.pdf

De la Cadena, Marisol

- (1992). "Las mujeres son más indias: Etnicidad y género en una comunidad del Cuzco". Revista Isis Internacional, 16: 25-45.

- (2000). Indigenous mestizos: the politics of race and culture in Cuzco, Peru, 1919-1991. Durham \& London: Duke University Press Books.

Degregori, Carlos Iván (1998). “Comunidades, instituciones, identidad” en C. I. Degregori (Ed.), Comunidades: Tierra, instituciones, identidad. Lima: Diakonia, CEPES-Arariwa.

Del Castillo, Laureano (1997). "Propiedad rural, titulación de tierras y propiedad comunal". Debate Agrario, 26: 59-79.

Diez Hurtado, Alejandro (2011). "Inversiones privadas y derechos comunales". Tiempo de opinión, 4: 22-31.

Dircetur (2014). Boletin Estadístico de Turismo 2014. Gobierno regional del Cusco.

Drinot, Paulo (2016). La Seducción de la clase Obrera. Trabajadores, raza y la formación del Estado Peruano. Lima: Instituto de Estudios Peruanos - IEP.

Eguren, Fernando; Del Castillo, Laureano; Burneo, Zulema (2009). Derechos de propiedad sobre la tierra en las comunidades campesinas, Cepes. Economía y Sociedad.

Escobar López, Daniel

- (2011). And suddenly the Kitchen fell from heaven: Poverty Alleviation, Gender Constructions and the State in Rural Northeastern Brazil. Tesis Maestría. Facultad de Antropología Social. Universidad de Estocolmo.

- (2012). "The Shifting Phases of a Commodity: Textiles and Ethnic Tourism on a Lake Titicaca Island". Totem: The University of Western Ontario Journal of Anthropology, Vol. 20: Iss. 1,Article 13. http://ir.lib.uwo.ca/cgi/viewcontent.cgi?article=1251\&context=totem

Espinosa Miñoso, Yuderkys (2014). "Una crítica descolonial a la epistemología feminista crítica" en Y. Espinosa Miñoso, D. Gómez Correal, K. Ochoa Muñoz (Eds.), Tejiendo de otro modo: Feminismo, epistemología y apuestas descoloniales en Abya Yala. Popayán: Editorial Universidad del Cauca.

Fabregat Esteva, Claudio (1970). Un mercado en Chinchero, Cuzco Anuario indigenista, 30: 213-254.

Friedmann, John (2010). "Place and Place-Making in Cities: A Global". Perspective, Planning Theory \& Practice, 11:2.

Fuller, Norma (2008). Turismo y cultura: entre el entusiasmo y el recelo. Lima: PUCP.

García, María Elena (2008). Desafios de la interculturalidad: Educación, desarrollo e identidades indígenas en el Perú. Lima: Instituto de Estudios Peruanos.

Harvey, Penélope (1989). "Género, autoridad y competencia lingüística. Participación política de la mujer en pueblos andinos". Documento de Trabajo No. 33, Serie Antropología N $^{\circ} 9$. Lima: Instituto de Estudios Peruanos.

Henrici, Jane (2007). “Género, Turismo y Exportación: ¿llamando a la plata en el Perú?" ANTHROPOLOGICA/ (25) diciembre: 83-101.

Huamán Tejo, Alejandra (2014). "Tenencia y valor de la tierra en la comunidad campesina de Colan: nuevas formas de apropiación, dimensiones del valor y tensiones comunales a partir de la entrada de la agroindustria de etanol". ANTHROPÍA, 12: 69-80.

Lamas, Marta (2007). “Complejidad y claridad en torno del concepto género” en ¿Adónde va la antropología? Disponible en: http://ebookbrowse.com/complejidad-y-claridad-lamas2007-pdfd143338160 
Lamphere, Louise (2005). "The domestic sphere of women and the public sphere of men: strengths and limitations of an anthropological dichotomy", en C. Brettell; C.Sargent, Gender in Cross-Cultural perspective. Prentice Hall.

Laurie, Nina (2011). "Gender Water Networks: Femininity and masculinity in water politics in Bolivia”. International Journal of Urban and Regional Research, Vol. 35(1):172-88.

Lugones, María (2008). “Colonialidad y Género". Tábula Rasa, 9: 73-101.

Malengreau, Jaques (1992). "Tierra, territorio y parcela en la reproducción social andina”, en Espacios Institucionales en los Andes. Instituto de Estudios Peruanos Universidad Libre de Bruselas. Versión en Castellano IEP Lima 1992. Pág. 35-36.

Márquez Porras, Raúl (2013). Construir la propiedad: Las formas y usos del derecho en una ocupación de Salvador de Bahía. Santiago de Compostela: Andavira Editora, S. L.

Montesinos Llinares, Lidia (2013). IRALIKU'K: La confrontación de los comunales. Etnografía e historia de las relaciones de propiedad en Goizueta. Tesis doctoral inédita, Departament d'Antropologia Cultural i Història d'Amèrica i Àfrica, Universitat de Barcelona.

Núñez del Prado, Óscar (1949). Chinchero, un pueblo andino del sur: algunos aspectos. Cuzco: Universidad Nacional del Cuzco.

Paredes, Julieta (2013). Hilando fino desde el feminismo comunitario. México: Cooperativa El Rebozo.

Rivera Cusicanqui, Silvia (2010). Ch’ixinakax utxiwa: una reflexión sobre prácticas y discursos descolonizadores. Buenos Aires: Retazos-Tinta Limón.

Sandoval, Pablo; Agüero, José Carlos (2015), "Aprendiendo a Vivir se va la vida" Conversaciones con Carlos Iván Degregori. Lima: Instituto de Estudios Peruanos IEP.

Seligmann, Linda J. (1989). "To Be in between: The Cholas as Market Women". Comparative Studies in Society and History, Vol. 31, No. 4 (Oct): 694-721.

Segato, Rita Laura (2014). "Colonialidad y patriarcado moderno: expansión del frente estatal, modernización, y la vida de las mujeres”, en Y. Espinosa Miñoso, D. Gómez Correal, K. Ochoa Muñoz (Eds.), Tejiendo de otro modo: Feminismo, epistemología y apuestas descoloniales en Abya Yala. Popayán: Editorial Universidad del Cauca

Tamayo Herrera, José; Zegarra Balcázar, Eduardo (2008). Las Elites Cusqueñas. Lima: JATH Velázquez, Sofía; Buechler, Hans; Buechler Judith-María (1996). The World of Sofía Velásquez: The Autobiography of a Bolivian Market Vendor. Auflage: Columbia Univ. Press.

Wardlow, Holly (2006). Wayward Women: sexuality and agency in a New Guinea society. Berkeley: University of California Press.

Weismantel, Mary (2001). Cholas and Pishtacos: Stories of Race and Sex in the Andes. The United States of America: University of Chicago Press.

Wollum, Jamie (2014). "El mundo del tejido: concepciones de identidad femenina y roles de género en Chinchero, Cusco, Perú" en Independent Study Project (ISP) Collection. 1853. http://digitalcollections.sit.edu/cgi/viewcontent.cgi?article=2885\&context $=\mathrm{isp}$ collection

Ypeij, Annelou (2012). "The Intersection of Gender and Ethnic Identities in the CuzcoMachu Picchu Tourism Industry: Sácamefotos, Tour Guides, and Women Weavers". Latin American Perspectives 39: 17.

Zorn, Elayne (2004). Weaving a Future: Tourism, Cloth, and Culture on an Andean Island. Iowa City: University of Iowa Press.

Referencias de internet

Diario Correo: 25 febrero 2014 
http://diariocorreo.pe/ciudad/huelguistas-obligan-a-comerciantes-a-cerrar-48449/ (último acceso 17 de enero del 2017)

Diario La República 26 febrero 2014

http://larepublica.pe/26-02-2014/cusco-se-volco-a-las-calles-para-exigir-gasoducto-y-elaeropuerto (último acceso: 17 de enero 2017) 